Cano, S. and Rubiano, O. 2020. "Dynamics Model of the Flow Management of Construction Projects: Study of Case." In: Tommelein, I.D. and Daniel, E. (eds.). Proc. $28^{\text {th }}$ Annual Conference of the International Group for Lean Construction (IGLC28), Berkeley, California, USA, doi.org/10.24928/2020/0110, online at iglc.net.

\title{
DYNAMICS MODEL OF THE FLOW MANAGEMENT OF CONSTRUCTION PROJECTS: STUDY OF CASE
}

\author{
Sandra Cano ${ }^{1}$ and Oscar Rubiano ${ }^{2}$
}

\begin{abstract}
This research reviews the issues associated with the obstruction of the workflow in the management of infrastructure construction projects in a public university in Colombia. The value flow of infrastructure projects is mapped, which allows showing the problems caused by waste in this flow. The issues are related to formal and informal policies and threads that condition workflows. The system dynamics model was used to study the systemic structure. The systemic model allows us to identify the cause-effect relationship between the elements in interaction in the model. Different states of intervention are simulated to suggest improvement actions by progressive elimination of wasteful activities in the value chain with the application of the principles and tools of Lean Construction in the short and medium terms.
\end{abstract}

\section{KEYWORDS}

System Dynamics, Lean Thinking, Value Stream Mapping, University infrastructure projects.

\section{INTRODUCTION}

In the university construction process study, it is revealed that the workflow of the construction project management infrastructure is affected by the application of policies that affect the efficiency of the project as well as excess steps in the flow of value to complete each construction phase in the project. Construction projects are developed in several stages and different annual budgetary periods: planning, hiring, construction, and finally, a phase of operation and maintenance. Financing for these projects is from the collection of a specific tax of Regional Government (RG) order, and it's transferred monthly to the university. Later, the contracting of the construction is carried out when the financial resource has been transferred, and the construction project has the highest level of constructability possible. The hiring must fulfill the principles of the Law of Public National Hiring in the context of the University Autonomy in this matter. In compliance with these regulations, processes that originate relations and flow between functional areas are settling down, and fulfillment promises of costs, time, reach, and quality, which not very often are fulfilled, are defined.

1 Prof., Escuela de Ingeniería Civil y Geomática, Universidad del Valle, Calle 13 No 100-00 edificio E48. Cali, Colombia, +(57) (2) 3212100 ext. 7231, sandra.cano@,correounivalle.edu.co, orcid.org/00000003-4257-6035

2 Prof., Escuela de Ingeniería Industrial, Universidad del Valle, Cali, Colombia, Calle 13 No 100-00 edificio E56, Cali, Colombia, oscar.rubiano@correounivalle.edu.co, orcid.org/0000-0001-5839-2076 
The production process of the project has a high number of formal interrelations defined in the systems of management of the institution. They also have other informal steps that originate according to additional personal and political criteria control and verification. These interrelations are identified with techniques that show the elements that directly hit the flow and the process value flow (Nash and Poling, 2008), and they are modeled dynamically to demonstrate the wastes elimination points in view to improve the flow (Cuatrescasas, 2010; Garcia, 2011). The application of methods and tools LEAN is used to improve the standards of answer and better use of the resources. This is obtained from the elimination of "wastes of work" in all the processes. (Hines and Rich, 1997).

\section{LEAN PRINCIPLES AND THE MAPPING OF THE VALUE STREAM}

The lean principles described by Jones and Womack (2002) in the improvement of the efficiency in value flows, they are:

1. To specify the value of the client from the point of view,

2. To identify the flow of value, including the activities that add value or do not add value for the client,

3. Allow that the project flows quickly without problems and through all the subprocesses,

4. To synchronize sub-processes capacity and demand, so that the work is realized in agreement with the scheme of pull production,

5. Reach perfection through continuous value flow improvement.

A value flow includes all process operations, even those that do not add value. The value flow mapping provides a graphical view of the elements of the process by which the client is willing to pay and for which not (Tapping and Shuker, 2003). Rother and Shook define "value stream" like "all the actions (that add value and that do not add it) that at those moments are required to produce a product or service.

\section{VALUE STREaM MaPPing (VSM)}

It is a graphical tool that integrates material and information flows utilizing the use of standardized icons in a graph, showing a "Mapping Big Picture" of the value flow. Jones and Womack (2002) define the VSM as the process of the map the flow of materials and information. This map is used to present the current processed state and after a map of the future state is proposed. VSM offers seven advantages:

1. It visualizes the flow of value as a whole.

2. It shows all the activities. Those that add and do not add value.

3. It relates the operations of the process to the supply chains, channels of distribution, and flows of información.

4. It demonstrates the relations between Production Control and Scheduling.

5. It provides a simple and common language for discussing the processes of the value stream.

6. It forms the base for a Lean implementation through the design of a production system based on the flow one by one for a family of products. 
7. It provides a "model" for the strategic planning, for the unfolding of the lean thought during its transformation in a Lean company.

\section{SYSTEM DYNAMICS}

The principles of circular thought (O'connor and McDermontt, 1998) and the associate tools have been applied to characterize the value flows. The Systems Dynamics modeling is an approach to understand the system complexity and its change, using differential equations to describe its dynamics (Forrester 1968). These processes can be studied like a set of the states available in the system, which is the central approach of the modeling (Garcia, 2012). Authors like Mota, Viana e Isatto (2010) suggest the use of the systems dynamics approach as a decision-making tool. They highlight that simulations can be used for processes improvement in construction.

\section{Symptoms of the Problem in the Management of Construction ProjeCtS IN UNIVERSITY INFRASTRUCTURE IN COLOMBIA}

The identification of problematic symptoms puts in evidence the necessity to improve the process to improve its efficiency. Some of these symptoms identified in the study of the production process of university infrastructure projects are:

- High impact on the production process due to the influence of external agents: national policies, restrictions for electoral periods, economic cycles, among others that cause delays in the transfer of the tax collected that finances the projects. The effect is the delayed start of recruitment activities..

- Low level of execution of the investment of financial resources for infrastructure projects. As a consequence, an extension of the contract term is required.

- Non-systematic planning related to the allocation of the collected tax. This planning problem results in the disorderly authorization of the projects to be contracted.

- The project requires adjustments. The adjustments need reworks before and during the hiring stage, as well as during the execution of the works. Additionally, these adjustments result in cost overruns for contract adjustments due to unplanned works..

- Processes that support the production have a slow response of the project on legal, administrative, or financial aspects and, therefore, slow decision-making by the medium or top management.

\section{Problem MaP}

Problem map is a simple tool that shows the factors directly relation whit parameters of scenarios to simulate as well as the indicators that show the performance of the system. Four indicators for the study are suggested. These indicators are presented in Figure 1. This figure shows the problem map. System performance indicators:

- Total time of annual plan projects

- Implementation efficiency

- Finished projects on the annuity

- Change in planned cost 


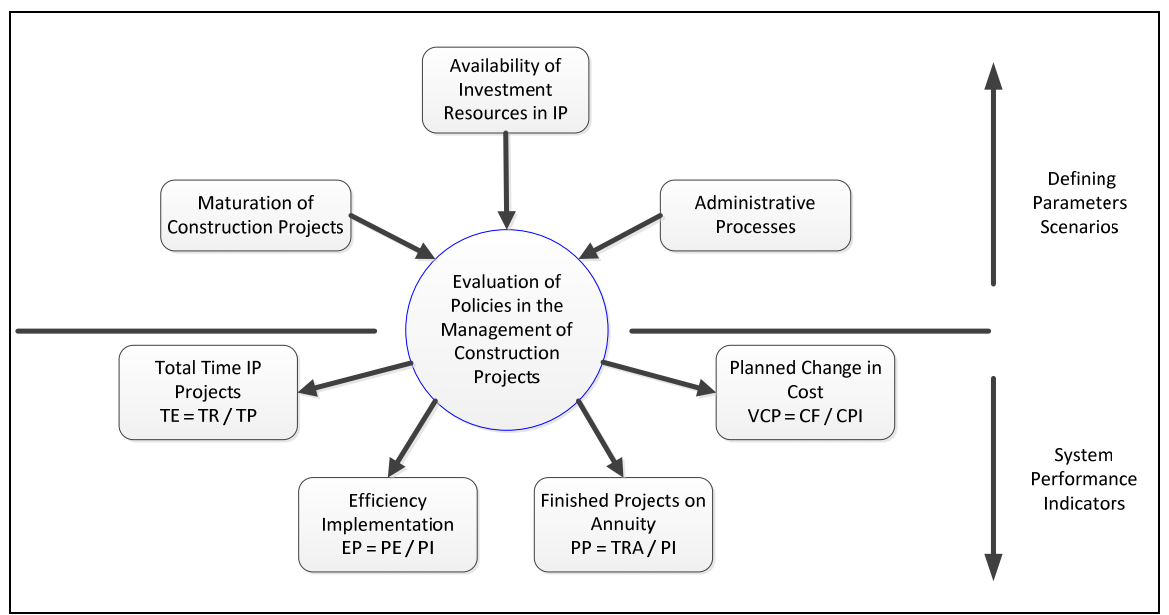

Figure 1: Problem map

\section{CASE STUDY}

\section{Current Status of the Management Process of University InFRASTRUCTURE Projects}

The annual budget to investment is estimated according to the past behavior of taxes collected. Budgets are elaborated down to take care of the diverse projects of investment according to the Strategic Institutional Plan. The Directive Council approves the projects to fund. These projects must have a high level of constructability. The transfer by tax collection should be made monthly by RG, however, it is not carried out regularly in this way.

After verifying the constructability of the project (rework) and confirm that the financial resources are available in cash, it is the moment to able to assign the funds to the contracting process, as long as not exceed the possible money. When the project requires constructability adjustments, this must be done, which consumes additionally 16 weeks (delays) on average. Later the hiring conditions are elaborated, and the tender goes ahead until to have a contract work. The term of each contract varies according to intervention magnitude and complexity (the average time is of 20 weeks). When construction is performing, if changes are necessary during the construction stage, the project return to the designer for adjustments related. Changes require additional financial resources and an increase in the term.

\section{Map of The Present State of The Value Stream}

In Figure 2, the map of the current state is presented. On it, the material and informational flows are identified as well as the interactions that exist in the process. This map was detailed with the use of another tool, the SIPOC Z. Streams and information related were identified and were shown at the map, Figure 3.

In this way, wastes are identified accurately, and the time that these steps consume going through the workstations wich being translated into delays that do not favor the flow of the process.

The map of Figure 3, the other nested flows of value in the main chain are shown. Improving each of these flows contributes to reducing times of delay in the mainstream, reducing or eliminating proceedings, and unnecessary controls. 
The area responsible for the coordination of construction centralizes the operations. This area depends on the administrative management of other areas for the project to flow. The main process has turned the client of other processes. These processes are identified as nested flows. In each nested flow, delays in the attention of the project appear, because it becomes a client of the nested chain and its attention depends on the sequence of arrival to the station.

\section{Interrelations of the Process of Execution of Projects of CONSTRUCTION OF INFRASTRUCTURE}

The systemic model helps to understand the causes of the behavior of the system. And how each element is part of it and how its components interact. The scenario simulation integrates different improvement actions in certain parts of the system and reflects the effects of these actions. Subsequently, alternatives are established that improve the current behavior identified on the basis of adjustments or changes in policies that directly affect management or the way of carrying out tasks.

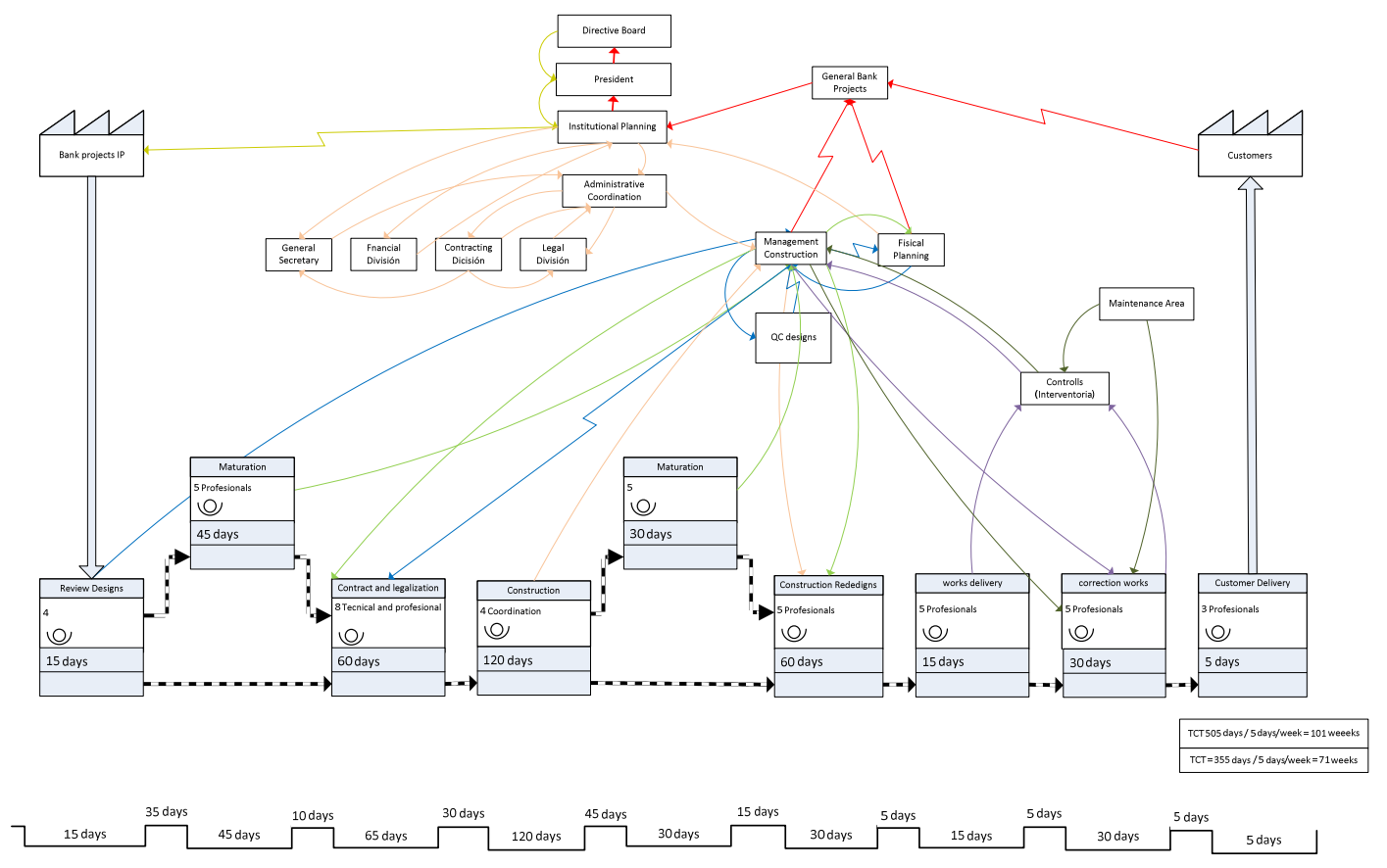

Figure 2: Map of the Present State, processes by which flow the project 


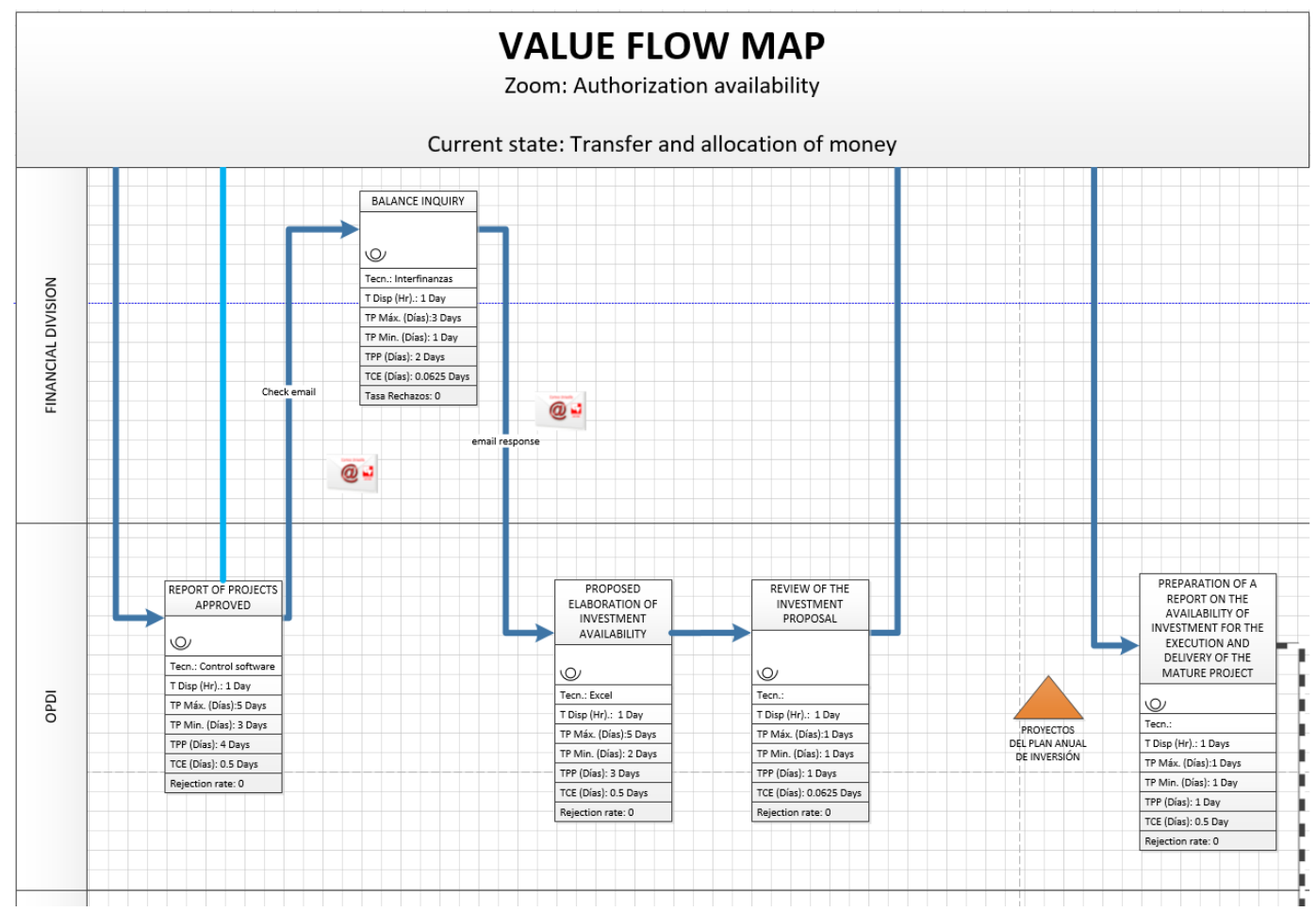

Figure 3: Detailed map of the Present State, steps of approval of the investment In Figure 4, elements are grouped in causal relations. The diagram shows four interrelated processes appear: a) Collection and transfer of taxes, b) Improvement of the construction capacity of the projects, c) Allocation of the transferred financial resources, d) Contracting of the works e) Construction of works and f) Problems associated with the adjustments required during the building.

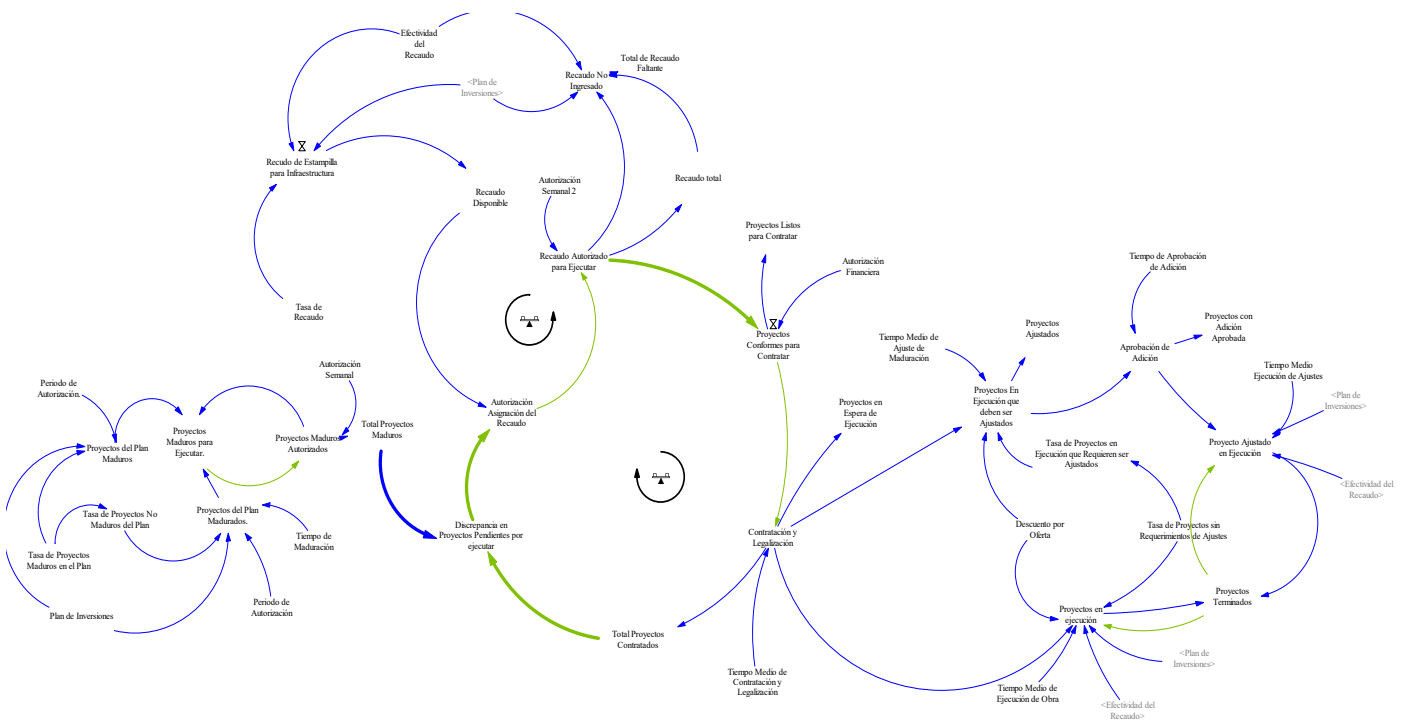

Figure 4: Causal diagram of relationships between factors and variables

(Original version in Spanish) 


\section{Structural Analysis of the Problem}

Three factors that improve the flow were identified. Each one is introducing to the system to improve intervention.

\section{USE OF INVESTMENT RESOURCES}

The administration of the RG makes the monthly collection, but it does not transfer it immediately. The first collection enters in April and the following with a delay of two months of the caused collection tax. The resources that are received from the month of September are not authorized for hiring by the conclusion of the fiscal year. The funds transferred in these last months are accumulated and pass to the following year. After consolidating the general balance of the institution, they are authorized to initiate the hiring of works related in the month of February or March of the following year. With this policy, the total of the projects of the Investment Plan (IP) is not completed in the predicted annuity. This situation, added to a scene in which the anticipated collection is not obtained, forces to postpone projects to be funded with resources of a future IP, in the best of the cases. A postponed project has a high probability of not executing[1], so the effectiveness in the execution of the IP is affected

This is due to that the clients realize a part of the work with their own resources, changing the initial project and must again initiate the process of a financing request. The project I can no longer have been required. The plan changes as much during the wait time that must start again from designs.

\section{Infrastructure Projects Maturation}

In the studied years, designs that allow resource allocation of IP were completed. This maturation consumed time and resources. Controls and reviews are placed at the end of the planning cycle but this does not achieve good results. They cause delays to achieve resource authorization.

\section{Own Complementary And Administrative Processes}

The execution of each passage of the main flow depends on other processes, subprocesses, or procedures which unfolded in all the interrelated dependencies. A considerable amount of formal and informal steps exists that consume time for their execution. These dependencies also take care of other projects different from infrastructure and tails in the attention that delays to the main flow of the construction projects.

\section{SYSTEM INTERVENTION}

Scenarios of intervention to the system are formed systematically integrate part each of the identified factors to evaluate their effect each one separately, later a combination of them with the same aim is realized. Simulation is a proposal of a better scenario to advisable performance to be implemented, and then the map of the future state is constructed.

\section{APPROVAL OF INVESTMENT}

Establish a cash transfer mechanism in line, with a bi-monthly frequency, will allow that the resources would be available and be subject only to other uncontrollable external conditions by the RG and the University. Considering that these resources are approved in the Annual Budget, subscribe to the budgetary availabilities as of the first working day 
of the year, continually monitoring the behavior of the transfer of the resources against the variability of the predicted collection. This proposal guaranteeing that the hiring process begins in a new way, and the contract is legalized when the fund is confirmed.

\section{Maturation of Designs}

Office responsible for the institutional planning must guarantee that all the designs of the construction projects of infrastructure, including in the IP count on certification of maturity to $100 \%$ by the project team in a collaborative atmosphere. Thus reworks on behalf of the lack of maturity of the designs are reduced. It is essential to anticipate sources of financing for possible adjustments required in the construction stage, because of situations of severe forecast during the maturity process, which form unforeseen project expenses during the phase of construction. The impact of this option is to avoid delays by the necessity to fit designs of greater reach during the construction phase.

\section{OWn ANd Supplementary Administrative Processes}

On these steps, most of the waste management processes are identified. Actions that cannot be ignored because they are part of the requirements of law or are strictly necessary to develop the method (contributory activities) are presented. The future state map Figure 5 shows the proposed improvements after simulation of detailed scenarios. The Rectory team must have support for administrative management of infrastructure construction projects. This team should be responsible for centralizing the operations that are currently performed independently in different areas. In this way, it can be established a cell office work to generate a one-piece flow. The involvement of this factor directly impacts the flow of information to expedite the physical flow.

\section{DYNAMICS MODEL}

\section{Problem FaCtors}

The Forrester diagram was constructed, Figure 5, and the feedback structure in the model, Figure 6, is identified. Factors that are represented in the diagram: the process of project maturation, availability of the collection, recruitment, and legalization, the execution of the work, and the adjustments during construction. The model has a section devoted to projects that were postponed because of the low effectiveness of the financial resources and the elements to obtain the performance indexes.

\section{MODEL VALIDATION}

By simulating the current status is verified that the model reproduces with high approximation the conditions of the current state. The simulation is performed for a horizon of 130 days, 2.5 years. The information is consistent with the actual situation of the management process under study.

\section{FORMULATION AND SIMULATION SCENARIOS}

The three factors under study offer a combination of seven scenarios, with which values for the indicators of the study are obtained. The results of the current state and simulation of each stage are related in Table 1. However, it is advisable to perform a normalization of the results in order to achieve a proper analysis, Table 2. The graphs, Figure 6, are resulting from the modeling of current state vs. future state (stage 5) Annex. The factors that configured scenarios are: Factor A: Approval of Investment, Factor B: Maturation of Designs, Factor C: Own and Supplementary Administrative Processes. 


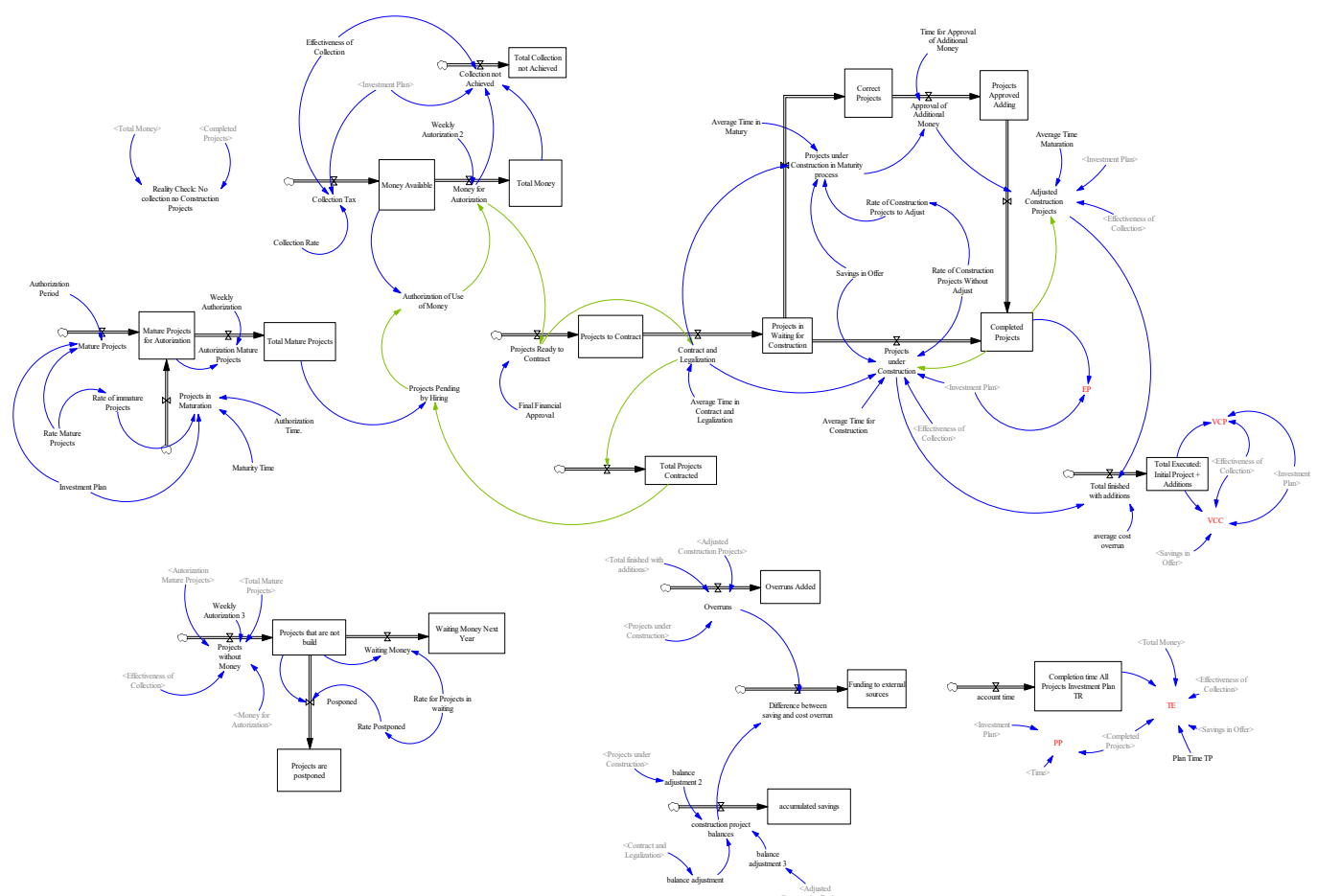

Figure 5: Forrester's process diagram

Table 1: Behavioral of indicators from analysis scenarios

\begin{tabular}{ccccccccc}
\hline \multirow{2}{*}{ SCENARIO } & $\begin{array}{c}\text { FACTOR M MX } \\
\text { FACTORS }\end{array}$ & EP & \multicolumn{2}{c}{ TE } & PP & VCP & Savings & Overrun \\
\cline { 3 - 9 } & \% IP & $\begin{array}{c}\text { No } \\
\text { Years }\end{array}$ & Weeks & \% IP & \% IP & \% IP & \% IP \\
\hline Current & Current & 91.2 & 1.923 & 101 & 10.66 & 1.80 & 3.8 & 5.6 \\
1 & A & 91.2 & 1.115 & 58 & 71.44 & 1.80 & 3.8 & 5.6 \\
2 & B & 91.2 & 1.846 & 96 & 15.23 & -4.0 & 3.8 & -0.2 \\
3 & C & 91.2 & 1.750 & 91 & 37.86 & 1.80 & 3.8 & 5.6 \\
4 & A,B & 91.2 & 1.058 & 55 & 76.00 & -4.0 & 3.8 & -0.2 \\
5 & A,C & 91.2 & 1.000 & 52 & 91.20 & 1.80 & 3.8 & 5.6 \\
6 & B,C & 91.2 & 1.750 & 91 & 37.86 & 1.80 & 3.8 & 5.6 \\
7 & A,B,C & 91.2 & 0.962 & 50 & 91.20 & -4.0 & 3.8 & -0.2 \\
\hline
\end{tabular}

Table 2: Normalization of the results

\begin{tabular}{ccccccc}
\hline SCENARIO & FACTOR & 1/TE & PP/0.9120 & 1/VCP & $\begin{array}{c}\text { Indicador } \\
\text { Global }\end{array}$ & $\begin{array}{c}\text { Mejora } \\
\text { Local }\end{array}$ \\
\hline Current & Current & 0.52 & 0.12 & 0.98 & 0.530 & Reference \\
1 & A & 0.89 & 0.78 & 0.98 & 0.937 & $82.5 \%$ \\
2 & B & 0.54 & 0.17 & 1.04 & 0.610 & $15.1 \%$ \\
3 & C & 0.57 & 0.42 & 0.98 & 0.659 & $24.3 \%$ \\
4 & A,B & 0.95 & 0.83 & 1.04 & 0.996 & $87.9 \%$ \\
5 & A,C & 1.00 & 1.00 & 0.98 & 1.047 & $97.5 \%$ \\
6 & B,C & 0.57 & 0.42 & 0.98 & 0.659 & $24.3 \%$ \\
7 & A,B,C & 1.04 & 1.00 & 1.04 & 1.084 & $104.5 \%$ \\
\hline
\end{tabular}




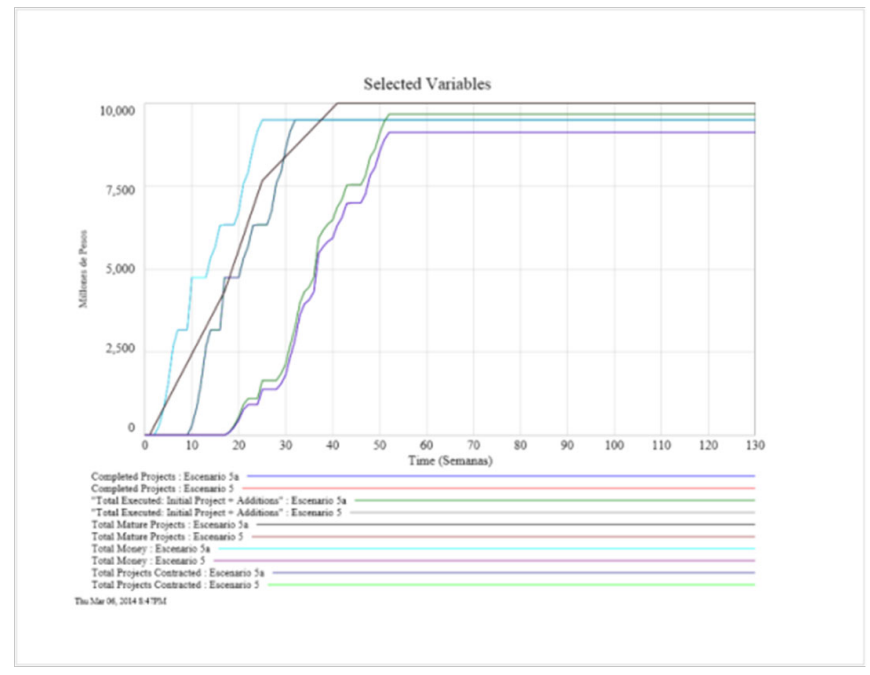

Figure 6: States Project

\section{FUtURe STATE MAP}

With the most suitable application scenario for the institution and with good performance indicators, a future state map, Figure 7, is proposed. The associated dynamic modeling corresponds to scenario 5 .

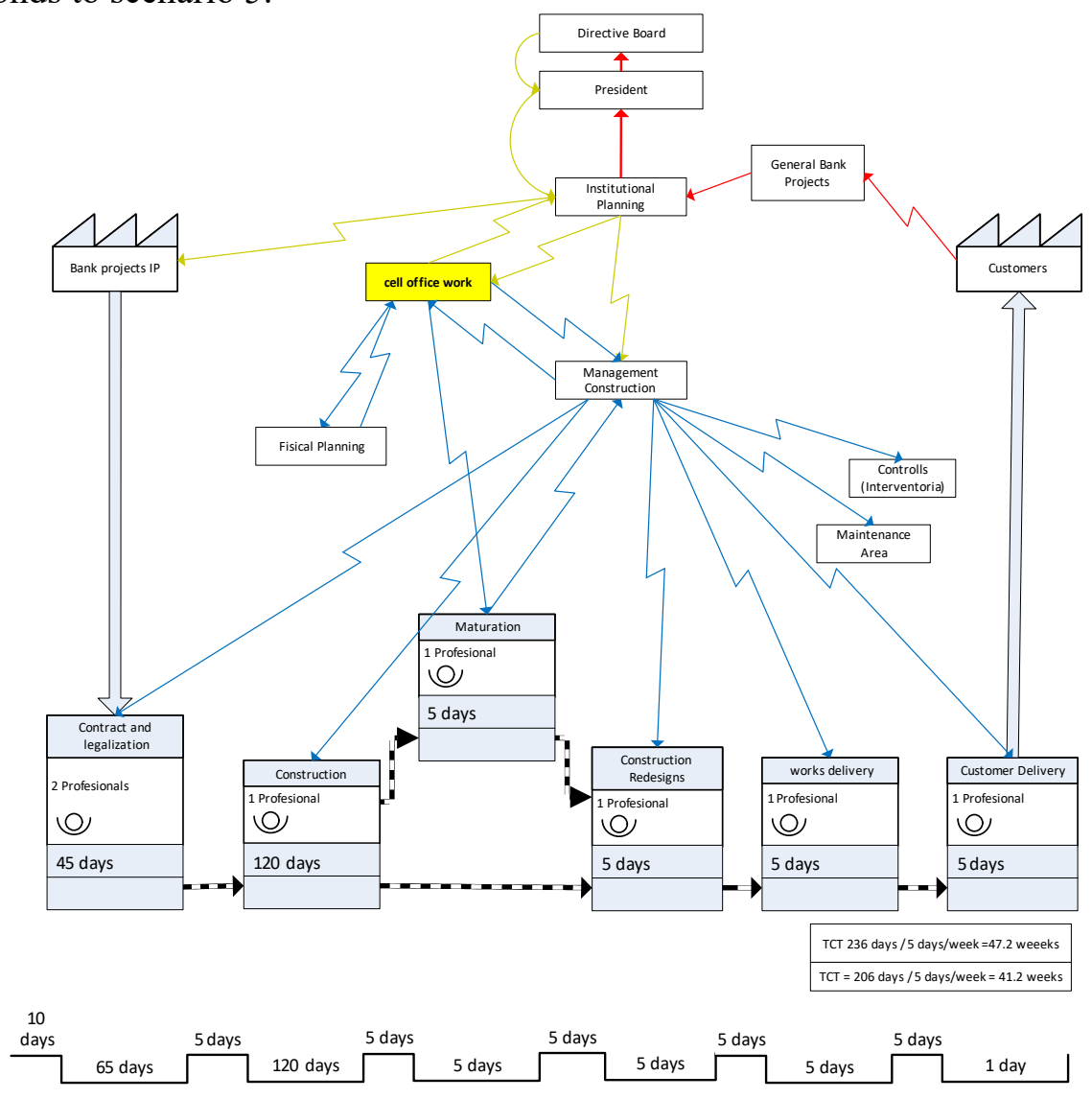

Figure 7: Future State Map processes that the project flows 


\section{RESULTS}

Scenario 5 results are reviewed: the efficient implementation of the ep plan: $91.2 \%$ is included in the offer discount. This efficiency is impacted by the reduction of $5 \%$ in the collection (it grossed $95 \%$ of the forecast) for shortages and cost overruns during the development works of the contract. The execution time of all projects plans, et: awarded run the IP in a year, 52 weeks, improvement over the current state in $97.5 \%$. Cost variation forecast, vcp is $1.8 \%$ above the IP, a tradeoff between the product offers savings and cost overruns for additional activities is presented, it is necessary to add the missing IP .

Scenario 7 intervention combining the three factors presented the best indicators; however, implementing improvement actions should be progressive. Intervene the collection transfer directly hits an $82.5 \%$ the performance improvement of the system, which should be the task of achieving management agreements to materialize the proposal of this simulation. Simultaneously all unnecessary administrative steps are eliminated (this simulation considered reduction steps in this first phase and subsequently the implementation of the work cell) and the.

\section{CONCLUSIONS}

The application of Lean tools, for this case, contributes to achieving both the economical use of personnel involved in the management process, such as an increase in value-added for customers. It validates that the symptoms of problems seen in a value flow should be analyzed with a systematic approach to understanding the root of the problems and their consequences, as well as the effectiveness of improvement actions.

It validates that the symptoms of problems seen in a value flow should be analyzed with a systematic approach to understanding the root of the problems and their consequences, as well as the effectiveness of improvement actions.

Lean Thinking has been developed by the manufacturers years with good results, especially when a business culture is consolidated around this thought in institutions like the study, parallel to the intervention of the factors you should build this culture removal waste as a common mission to help streamline the flow in this and other business processes.

Mapping the value stream is essential to identify underlying structures in the value flow, in addition to activities that add no value, to propose formulating structural measures to expedite the flow of the mainstream, and projects to can fulfill planned targets.

\section{RECOMMENDATIONS}

The implementation of the work cell in the office is an alternative to improve the efficiency of the system, a more detailed study must be performed to clarify the impact of its operations and use both the main flow and nested flows and a reduction of personnel involved in this process to improve efficiency.

The implementation of the work cell in the office is an alternative to improve the efficiency of the system, a more detailed study must be performed to clarify the impact of its operations and use both the main flow and nested flows and a reduction of personnel involved in this process to improve efficiency.

The intervention in the maturity of the designs should be considered as a collaborative task and must use new information technologies such as Building Information Modeling, BIM. 
The institution must define a process for the selection of designers and consultants based on criteria that contribute to achieving high standards of design constructability. A selection process of construction contractors must be defined as part of the creation of a proper supply chain for the project, especially in the construction phase.

The organization must foster Lean projects, especially those related to construction, building a culture of waste disposal as a joint mission to help streamline the flow in this and other business processes.

In the process of transition to lean management of construction projects, it is feasible that, as interventions are implemented college propose the implementation of its IP in a horizon of at least two years so it can be performed, adjusting to the institutional capacity reality, in such a way that in the measurement that is realized these adjustments will be able to be realized commitments of execution near the annuity.

\section{ACKNOWLEDGMENT}

The authors express their gratitude to the directors of Universidad del Valle who provided the information for the completion of this work which is exploratory in nature.

\section{REFERENCES}

Cuatrescasas L. (2010). Lean Management: La gestión competitiva por excelencia.( Lean Management: The competitive management by excellence) Profit Editorial. Barcelona.

García, J. M. (2011). Dinámica de Sistemas Avanzado (Advanced Systems Dynamics). Juan Martín García.

García, J. M. (2012). Dinámica de Sistemas - Conceptos (Systems Dynamics - Concepts). Juan Martín García.

Greif, M. (1993). La fábrica visual: Métodos visuales para mejorar la productividad (The Visual Factory: Visual Methods to Improve Productivity), ProductivityPress.

Hines, P. and Rich, N. (1997). The seven value stream mapping tools. International Journal of Operations and Production Management, Vol. 17, No. 1, pp.46-64.

Jones, D. and Womack, J. (2002). Seeing the Whole: Mapping the Extended Value Stream. Brookline, MA: The Lean Enterprise Institute. Brookline, Massachusetts.

Mota, B., Viana, D. and Isatto, E. (2010). Simulating the Last Planner with Systems Dynamic. Proceedings IGLC-18, July 2010, Technion, Haifa, Israel.

Nash, M. and Poling, S. (2008). Mapping the Total Value Stream.Taylor and Francis Group, LLC.

O'Connor J, McDermontt I. (1998). Introducción al Pensamiento Sistémico (Th The Art of Systems Thinking e Art of Systems Thinking). Editorial Urano.

Rother, M. and Shook, J. (2003).Learning to see: Value stream mapping to create value and eliminate muda.The lean enterprise institute.

Tapping, D. and Shuker, T. (2003). Value Stream Management for the Lean Office, New York: Productivity Press. 